\title{
Assessing management options for weed control with demanders and non-demanders in a choice experiment
}

\author{
Fredrik Carlsson $^{\mathrm{A}}$ \\ Mitesh Kataria ${ }^{B}$ \\ Working Papers in Economics no. 208 \\ May 2006 \\ Department of Economics \\ School of Business, Economics and Law \\ Göteborg University
}

\begin{abstract}
The yellow floating heart is a water weed causing nuisance problems in Swedish watercourses. An economic analysis of this is required where various management options are considered. The benefits of a management program are to a large extent recreational. Using a choice experiment we estimate the benefits of a weed management program and perform a cost-benefit analysis of different management programs. In order to be able to distinguish between those who have a demand for a program from those who do not, we introduce a way to distinguish demanders from non-demanders in the choice experiments. The advantage of our suggested approach is that we can more clearly distinguish between conditional and unconditional willingness to pay. In the empirical study we find that a share of the respondents are non-demanders. The demander willingness to pay still justifies cutting the weed in certain places in the lake, given that we use a simple cost-benefit rule.
\end{abstract}

Keywords: Choice experiments, invasive species, non-demanders, bivariate probit JEL-classification: Q25, Q26, Q51

Acknowledgments: Carlsson acknowledges financial support from Sida to the Environmental Economics Unit at Göteborg University. We are most grateful for comments from Peter Frykblom, Elina Lampi and Daniel Larson.

${ }^{\text {A }}$ Department of Economics, Göteborg University, Box 640, 40530 Göteborg, Sweden. Ph: +46 31 7734174, email: fredrik.carlsson@economics.gu.se

${ }^{B}$ Department of Economics, Swedish University of Agricultural Sciences. Box 7013, 75007 Uppsala, Sweden. Ph: +4618 671725, e-mail: mitesh.kataria@ekon.slu.se 


\section{Introduction}

The yellow floating heart (Nymphoides peltata) is an aquatic plant classified as a serious weed in Sweden. Like many other aquatic weeds, it was initially introduced for its quite appealing appearance and attractive and colorful flower. A single plant was planted in 1933 in Lake Väringen, which by 1975 had spread to cover an area of $0.45 \mathrm{~km}^{2}$ (Josefsson and Andersson, 2001). Today there are about 40 affected sites in Sweden (Larsson and Willen, 2006). Nuisance problems are caused by overgrown water bodies, which interfere with boat traffic as well as recreational activities such as fishing, swimming and canoeing (Josefsson and Andersson 2001). The effect on the ecosystem is not fully known. Mechanical as well as biological and chemical control attempts have been made in order to make the weed extinct, but in many instances without success. The current control practice is to mechanically cut the weed. As the yellow floating heart has a vegetative propagation, it is believed that the weed together with fragments of it should be collected and removed from the sites as they otherwise can conduce to further spread.

The purpose of this paper is to estimate the benefits of a weed management program and compare them with the corresponding costs. However, a weed management program can be designed in different ways, not the least when it comes to where in the water system one should cut. It might be too costly to cut the weed in an entire lake. It is therefore of interest to investigate the benefits of various strategies. In order to estimate these benefits we conduct a choice experiment study, where users and potential users of the lake are asked to make choices between different management options. The difference between the options is where in the lake the weed is cut and the cost for the people in the municipality. The reason for using a stated preference method is that it is impossible for us to observe the various management options and hence it is not possible to observe revealed preferences for the management options. We opt for a choice experiment and not a contingent valuation survey because we are interested in measuring the willingness to pay (WTP) for a number of attributes of the management options. ${ }^{1}$ In a choice experiment, individuals are given a hypothetical setting and asked to choose their preferred alternative among several alternatives in a choice set. The participants are usually asked to perform a sequence of such choices. Each alternative is described by a number of attributes or characteristics. This survey method thus allows us to estimate the marginal rate of substitution among different attributes. For overviews of choice

\footnotetext{
${ }^{1}$ See for example Nunes and van den Bergh (2004) for an application of contingent valuation and the travel cost method for valuing protection against an invasive species.
} 
experiments, see Louviere, Hensher and Swait (2000) and Alpizar, Carlsson and Martinsson (2003).

The survey was sent out to a random sample of people in the municipality where the lake is situated; thus, we did not target only, say, boat owners, nor did we conduct on-site interviews. This means that in our sample there are expected to be a number of respondents defined as non-demanders in the sense that they are not willing to pay anything for the removal of the weed in the lake. It is important to appropriately identify these non-demanders, so that the preferences we elicit are the preferences of the demanders only. In choice experiment surveys the common approach is to include an opt-out alternative in each choice set (Bennett and Blamey, 2001). The opt-out alternative, however, does not distinguish between demanders and non-demanders. In this paper we suggest and test a way of dealing with non-demanders, where we identify non-demanders before the actual choice experiment and where only those who demand a policy are asked to do the choice experiment. The econometric model as well as the design of the survey differ from what is conventionally used in the literature. One interesting aspect of this approach is that we can make a clear distinction between unconditional and conditional WTP; the conditional being the WTP for demanders, which provides the policy-maker with additional information about how important the public good is to the welfare of the demanders.

The rest of the paper is organized in the following way. In Section 2 we present the design of our choice experiment, followed by Section 3 where we present the econometric model and discuss how to distinguish demanders from non-demanders. In Section 4 we report the results of the choice experiment and Section 5 concludes the paper.

\section{The Choice experiment}

The choice experiment concerns Lake Väringen, located in the municipality Lindesberg in Sweden. Lake Väringen covers $19 \mathrm{~km}^{2}$, and the water weed is widespread in various parts of this lake. The lake is shallow and eutrophic. Soil water from a nearby village and wastewater from the local paper mill run to the lake, which could have a positive effect on the growth of the water weed. The possible surface area for weed colonization is estimated to somewhere between $30-50 \%$ of the total lake surface (Eriksson, 2005).

The survey was sent out to a random sample of individuals living in the municipality of Lindesberg. The questionnaire consisted of three parts. The first contained questions regarding the respondent's perception about the waterweed in Lake Väringen. The second part contained the choice experiment, and the third part questions about the respondent's socio- 
economic status. Pre-tests and interviews together with one pilot study were conducted in the process of designing the questionnaire.

The attributes and the levels of the attributes are presented in Table 1. Each choice set contains two alternatives. The choice sets were created simultaneously in the sense that the design was selected from the collective factorial (Louviere, 1988). ${ }^{2}$ From the full collective factorial we used the D-optimal linear design routine in SAS (Kuhfeld, 2001) to select 28 choice sets. These were then blocked into four versions, each containing seven choice sets. Because of budgetary constrains, the design was restricted to only estimate main effects, i.e. the effect of changing the level of a single attribute. The main effect design assumes that all omitted interaction effects are zero.

Table 1: Attribute and attribute levels

\begin{tabular}{|l|c|c|}
\hline \multicolumn{1}{|c|}{ Description } & Attributes & Levels \\
\hline $\begin{array}{l}\text { Control of the weed in specific } \\
\text { areas of the lake }\end{array}$ & $\begin{array}{c}\text { Housing area nearby Frövi } \\
\text { Bathing place } \\
\text { Canoe track } \\
\text { Boat place }\end{array}$ & $\begin{array}{c}\text { Yes, No } \\
\text { Yes, No } \\
\text { Yes, No }\end{array}$ \\
\hline $\begin{array}{l}\text { Control of the water weed in } \\
\text { remaining parts of the lake }\end{array}$ & Remaining part of the lake \\
$\begin{array}{l}\text { The total cost for the household } \\
\text { if the alternative was chosen }\end{array}$ & Cost & $0,40,80,100 \%$ \\
\hline
\end{tabular}

In the questionnaire the respondents were informed about the occurrence of the waterweed in Lake Väringen, and specific areas where weed control could be of interest were marked on a map. The map, together with an example of a choice situation, is presented in Appendix A. We also included a so-called cheap-talk script in the questionnaire. Initially suggested by Cummings and Taylor (1999), cheap talk is an attempt to bring down the hypothetical bias by thoroughly describing and discussing the propensity of respondents to exaggerate stated WTP. Both Carlsson, Frykblom and Lagerkvist (2005) and List and Sinha

\footnotetext{
${ }^{2}$ From the full factorial design $(65,536$ choice sets), sets with completely dominating alternatives were deleted (in total 16,700 sets). Moreover, we wanted to avoid "too" dominant choice sets. This was done by calculating so-called code sums for each option (Wiley, 1978). In order to calculate the code sum, we arrange the levels of the attributes from worst to best, the lowest attribute level being assigned a value of 0 , the next 1 and so on. Thus, for a three-level attribute, the highest value is 2 . The code sum is the sum of all these values for each option. By comparing the code sums, one can get a simple indication of which alternatives are particularly dominant, although not completely dominant. This is obviously a crude approach, and in order for it to work reasonably well, the utility difference between two levels should not differ too greatly across attributes. In our case, we deleted all design alternatives with a code sum difference exceeding 4; there were altogether 13,369 such alternatives from a total of 48,836 alternatives.
} 
(2004) show how cheap talk scripts can be used in choice experiments order to reduce hypothetical bias. The script reads as follows:

The experience from previous similar studies is that people often respond in one way but act differently. It is particularly common that one states a higher willingness to pay than what one actually is willing to pay.

We believe this is due to the fact that one does not really consider how big an impact an extra cost actually has on the family budget. It may also be that one forgets that there are other lakes than Väringen that one could go to. If you have another idea or comment on what this behavior depends on, please write this down on the last page of the questionnaire. This will help us in our research.

\section{Identification of non-demanders and econometric analysis}

Many choice experiments include an opt-out alternative in each choice set, e.g. a no-purchase decision, a status-quo situation or something similar. There are several arguments for doing this: discrete welfare measures can be distorted if an opt-out alternative is not included, and including an opt-out alternative resembles a real situation better. In this paper we want to look at an alternative to including a status-quo alternative, by asking before the actual choice experiment whether the respondent actually wants to have the weed cut or not. Those who answer yes continue with the choice experiment that concerns how it is going to be cut, while those who answer no do not answer the choice experiment. We call the former group demanders and the latter non-demanders. Consequently, those who answer the choice experiment have a positive WTP for at least one of the attributes, while those who do not answer the choice experiment have a zero WTP for all attributes. ${ }^{3}$ This way of identifying non-demanders is different from including an opt-out alternative, since in the latter case not only non-demanders choose the opt-out. For example, a respondent may for some choice sets think that given the attribute levels, the opt-out is a better alternative. With our approach there is a clear distinction between the two groups of respondents. This will then provide policymakers with additional information to understand how important the public good is to different groups of people. Furthermore, as we will show, we can in the econometric analysis identify factors that explain the probability of being a demander.

The inspiration from this way of identifying non-demanders comes from the so-called spike models in contingent valuation; see e.g. Kriström (1997), Haab (1999) and Clinch and Murphy (2001). Similar to our approach, a screening question is often used to identify respondents with a zero WTP and the estimated WTP distribution contains a spike at zero WTP. With choice experiment data we do not estimate the WTP distribution for a particular

\footnotetext{
${ }^{3}$ It should be noted that there might even be respondents who actually like the weed, and would thus have a negative WTP for cutting the weed. We will, however, assume that the WTP for the non-demanders is zero.
} 
scenario; instead we estimate the preferences for a number of attributes. From this we can then calculate the WTP for a particular scenario. Consequently our econometric model is somewhat different from what has been used in the contingent valuation literature, although our specification could actually be used for contingent valuation data as well. We use a random effect bivariate probit model with sample selection when analyzing the responses. The bivariate probit model with sample selection was initially proposed by Wynand and van Praag (1981). We have two variables that we can potentially observe:

$y_{1}=1$ if individual $i$ chooses alternative A in a particular choice set ( 0 otherwise),

$y_{2}=1$ if individual $i$ is a demander ( 0 otherwise),

where alternative $\mathrm{A}$ is defined as the alternative with a higher cost in a particular choice set. Remember that the choice experiment is a repeated binary choice experiment with generic alternatives. However, we only observe $y_{1}$ if $y_{2}$ equals 1 . The observations of these two variables are in turn based on two latent functions:

$$
\begin{aligned}
& y_{1}=1 \text { if } U_{1}^{*}\left(=U_{A}-U_{B}\right)=\beta_{1} x_{1}+\varepsilon_{1}>0, \\
& y_{2}=1 \text { if } U_{2}^{*}\left(=U_{\text {cut }}-U_{\text {no cut }}\right)=\beta_{2} x_{2}+\varepsilon_{2}>0 .
\end{aligned}
$$

The two latent functions can be interpreted as general index functions or as utility functions. For example, if we let $U_{2}^{*}$ denote the utility of cutting the weed, an individual would only say yes to cutting the weed if $U_{2}^{*}$ is greater than zero. Similarly, if we let $U_{1}^{*}$ denote the difference in utility between alternative $\mathrm{A}$ and $\mathrm{B}$ in the choice experiment, an individual would choose alternative A if $U_{1}^{*}$ is greater than zero. Our formulation is consistent with a random utility framework in the sense that we introduce a random component of the utility functions. We assume that the error terms have a standard normal distribution with a correlation, which gives us a bivariate probit model with selection (Greene, 2000):

$$
E\left[\varepsilon_{1}\right]=E\left[\varepsilon_{2}\right]=0 ; \operatorname{Var}\left[\varepsilon_{1}\right]=\operatorname{Var}\left[\varepsilon_{2}\right]=1 ; \operatorname{Cov}\left[\varepsilon_{1}, \varepsilon_{2}\right]=\rho
$$

The sample selection model is appropriate in our case since only a sub sample (demanders) of the full sample answers the question of the choice experiment. The population regression for the full sample of respondents may be written as: 
$E\left(U_{1}^{*} \mid x_{1}\right)=\beta_{1} x_{1}$

The regression function for the sub sample with demanders may be written as:

$E\left(U_{1}^{*} \mid x_{1}, U_{2}^{*} \geq 0\right)=\beta_{1} x_{1}+E\left(\varepsilon_{1} \mid U_{2}^{*} \geq 0\right)=\beta_{1} x_{1}+E\left(\varepsilon_{1} \mid \varepsilon_{2} \geq-\beta_{2} x_{2}\right)$.

The regression function of the sub sample of demanders is the same as the population regression function if and only if the conditional expectation of the second term in equation (5) is zero. A correlation between $\varepsilon_{1}$ and $\varepsilon_{2}$ will cause inconsistent estimates, i.e. sample selection bias. Using the bivaritate probit model with selection, we can adapt Heckman's selection model to the binary choice situation and correct for the potential selection bias.

In order to also account for unobserved heterogeneity in taste, we allow tastes to vary in the population by assuming that the coefficients vary randomly among respondents in the choice experiment. ${ }^{4}$ The utility function for demanders can be decomposed and written as:

$U_{1}^{*}=\bar{\beta}_{1} x_{1}+\widetilde{\beta}_{1} x_{1}+u$,

where $\bar{\beta}_{1}$ is the population mean and $\widetilde{\beta}_{1}$ is normally distributed in the population with mean $b$ and covariance W. Do note that the last two terms in the utility function are random, meaning that $\varepsilon_{1}=\tilde{\beta} x_{1}+u$. Using this specification we obtain the population mean as well as the individual deviations from the population mean of the random parameters in the model. We assume that all the attributes of the choice experiment are randomly and independently normally distributed with the exception of the coefficient of the cost attribute, which is assumed to be fixed. Furthermore we assume that randomly distributed parameters are constant across the choice situations for each individual. This reflects an underlying assumption of a stable preference structure for all individuals across the choice experiment (Train, 1998). Derivation of the random parameter probit model can be found in Hausman and Wise (1978).

\footnotetext{
${ }^{4}$ This has become almost the standard approach to analyse choice experiment data; see e.g. Layton and Brown (2000) and Carlsson et al. (2003).
} 
The utility function $U_{1}^{*}$ is assumed to be a linear function of the attributes of the choice experiment. This means that we can estimate the marginal WTP from the estimated parameters by scaling the attribute coefficient with the cost coefficient (Hanemann, 1984). However, this is the conditional marginal WTP since it is the WTP given that the respondent is a demander. In order to obtain the sample marginal WTP we have to consider the nondemanders which by definition have a zero WTP. The sample WTP can simply be calculated as:

$E[W T P]=P[$ Demander $] * E[W T P \mid$ Demander $]+P[$ Non - demander $] * E[W T P \mid$ Non-demander $]$

where $E[W T P \mid$ Non-demander $]=0$. The zero WTP for non-demanders, given that the cost is zero, implies that the non-demanders experience neither utility, nor disutility from the weed management program. Hence, the non-demanders get disutility by paying for a weed management alternative per se regardless of what attribute levels the alternative has to offer. Furthermore, the sample WTP of the attributes is restricted to be non-negative as long as the demanders on average have a positive WTP for the attribute in question.

\section{Results}

\subsection{Descriptive results}

The survey was sent out in 2005 to a random sample of individuals 18-75 years old living in the Lindesberg municipality. A reminder was sent out 2 weeks after the main survey to those who had not replied. After deducting the number of questionnaires returned because the respondent had moved, there were 993 questionnaires sent out. In total 299 (30\%) respondents returned the questionnaire. The sample included 55 questionnaires where neither the demand question nor the choice-experiment had been answered (in fact, 31 of these questionnaires were returned completely blank). For these 55 observations we applied a conservative approach and assumed that these respondents are non-demanders. ${ }^{5} 26$ respondents were dropped from the sample because of missing observations. 15 of these had not answered the choice experiment and thereby had not accepted any of the bids in the experiment, although they did state that they wanted the weed to be cut. 11 observations were

\footnotetext{
${ }^{5}$ The conservative approach for these answers is adapted as it resembles a market situation. Either you buy the product, or you don't. In this context, delayed decision is considered as a no-purchase alternative.
} 
dropped because of missing values for various reasons. In total, 273 questionnaires are used in the analysis. Descriptive statistics of these are presented in Table 2 below.

Table 2: Descriptive statistics

\begin{tabular}{llcc}
\hline \multicolumn{1}{c}{ Variable } & \multicolumn{1}{c}{ Description } & Mean & Stdv. \\
\hline Age & Respondent age in years & 48.95 & 15.77 \\
Male & 1 if male respondent & 0.67 & 0.47 \\
Kid & 1 if household has children & 0.32 & 0.46 \\
Distance & Distance in km to the lake & 18.56 & 14.15 \\
Don't know distance & 1 if respondent did not state distance & 0.19 & 0.39 \\
Boat & 1 if respondent has boat at the lake & 0.10 & 0.30 \\
Canoe & 1 if respondent uses the lake for canoeing & 0.04 & 0.19 \\
Cabin & 1 if respondent owns cabin by the lake & 0.04 & 0.19 \\
Awareness & 1 if respondent is aware of the problem with & 0.55 & 0.50 \\
& water weed & & 1.47 \\
Problem & 5 if water weed is seen as a serious problem and & 2.44 & \\
& 1 if not seen as a problem at all. & & \\
\hline
\end{tabular}

Half of the respondents in the sample seem to have been aware of the waterweed in Lake Väringen prior to receiving the survey; however, the sample did not generally perceive the water weed as a very big problem. The mean age of the respondents was almost 49 years and a relatively large fraction of them were male. $10 \%$ have a boat by the lake, $4 \%$ use the lake for canoeing and $4 \%$ own a cabin by the lake.

\subsection{The random bivariate probit model with selection}

In the demand/non-demand equation we include a number of socio-economic characteristics as explanatory variables. In the utility function we include all the attributes of the choice experiment. In addition we include two interaction variables; one where we interact the canoe attribute with whether the respondent uses the lake for canoeing, and one where we interact the boat place attribute with whether the respondent owns a boat by the lake or not. All attributes in our model are assumed to be random and normally distributed except for the cost one, which is assumed to be fixed. The distribution of the marginal WTP has then the same distribution as the attribute. Moreover, all attributes except remaining parts and cost are binary variables. Remaining parts is measured as the percent of the remaining parts that is cut, and cost is measured in SEK. ${ }^{6}$ The model is estimated with 1,000 Halton draws using Nlogit 3.0. The result of the model is presented in Table 3.

\footnotetext{
${ }^{6}$ At the time of the survey $1 \mathrm{USD}=7.6 \mathrm{SEK}$.
} 
Table 3: Random bivariate probit model with selection (p-values in parentheses).



First of all, if we look at the bottom of the table we see that there are 105 non-demanders; but of these 32 did not answer relevant questions in the questionnaire and are therefore not included in the regression. Given a positive demand, there were in total 1,023 choices made in the experiment. The correlation coefficient, $\rho$, is highly significant meaning that we can not reject the hypothesis of a selection effect.

If we then look at the selection equation we see that the gender and age of the respondent have a significant effect on the probability of being a demander. The negative sign implies that males are less likely to have a positive demand for cutting the weed, and the negative coefficient for age indicates that older respondents are less likely to have a positive demand for cutting the weed. Respondents with at least one child under 18 in the household are also less likely to have a positive demand. As expected, respondents living close to the lake are more likely to have a positive demand for cutting the weed.

Let us now look at the responses to the choice experiment. Remember that we have defined alternative A as the more costly alternative. The intercept is negative and significant, 
meaning that all else equal and controlling for the difference in cost, a respondent is more likely to choose the lower cost alternative. All other coefficients, apart from the cost coefficient, are positive and significant, except for the canoe track interaction variable. The interaction between boat place and if the respondent owns a boat is also positive and significant, which means that boat owners are willing to pay more than others for having the weed cut at the boat place. Moreover, all of the estimated standard deviations of the random attribute parameters are significant. The significance is a sign of heterogeneity in preferences among the respondents. The standard deviations are sizeable in comparison with the mean effects. This means that there is a large unobserved heterogeneity. It also means that there is a non-negligible probability that people have the reverse preference for a particular attribute; in our case in particular for the canoe attribute and the remaining parts attribute. The probability of a reverse preference is due to the assumption of a normal distribution. ${ }^{7}$ One interesting aspect of random parameter models is that it is possible to retrieve individual-level parameters from the estimated model, using Bayes' Theorem. This means that we can get a notion of where a specific individual is placed in the estimated distribution; see Train (2003) for details. If we do this we find that for the canoe attribute, $25 \%$ of the respondents have the reverse sign, and for the remaining parts attribute, $10 \%$ have the reverse sign. For the other attributes, none or only a few respondents have the reverse sign. So the problem of a reverse sign is not particularly severe.

Using the results of the estimated model we can estimate marginal WTP or part-worth of an attribute. This is obtained by simply taking the ratio of the attribute of interest using the coefficient for cost as the numeraire (Hanemann, 1984). Hence, the marginal WTP is simply the marginal rate of substitution between one of the attributes in the choice experiment and the cost attribute. However, note that this is the marginal WTP conditional on a positive demand. We therefore also report the unconditional WTP, which is calculated using the sample fraction of respondents with a positive WTP. ${ }^{8}$ The WTP for boat place and canoe track are calculated at the mean of the conditional sample. Standard errors are calculated with the Delta method (Greene, 2000).

\footnotetext{
${ }^{7}$ Unfortunately, a log-normal distribution, which would restrict the sign of the coefficient, is not available in Nlogit for this type of model; in addition, a log-normal distribution is known to give extremely high and "unreasonable" mean estimates in some instances as well as difficulties of convergence (Hensher and Greene, 2003). We also tried with imposing constraints on the distribution from which the random parameter estimates are drawn. However, this caused a problem of convergence.

${ }^{8}$ Another issue if we want to calculate a sample average WTP is how we treat those not responding to our survey. A very conservative treatment would be to assume that all non-respondents have a zero WTP for all the attributes, i.e. they are non-demanders too. Here we will assume that those who did not respond are represented by those who did respond to the survey.
} 
Table 4: Marginal willingness to pay for attributes; standard errors in parentheses.

\begin{tabular}{lcc}
\hline & Conditional WTP & Unconditional WTP \\
\hline Housing area & 197 & 121 \\
Bathing place & $(22)$ & $(14)$ \\
& 540 & 332 \\
Canoe track & $(38)$ & $(23)$ \\
& 103 & 63 \\
Boat place & $(22)$ & $(14)$ \\
Remaining parts & 211 & 130 \\
& $(22)$ & $(14)$ \\
& 2.9 & 1.8 \\
\end{tabular}

First of all, there is a clear difference, of course, between the conditional and unconditional WTP, because a large fraction of the respondents stated that they are not willing to pay anything at all to have the weed cut. Second, the most important area to be cut is the bathing place; the respondents are willing to pay around 300 SEK to have the weed cut there. The second and third most important areas are the boat place and the housing area, where the respondents are willing to pay around 100 SEK to have the weed removed. Finally, we have the least important attribute, which is the canoe track; the respondents are willing to pay only around 60 SEK to have the weed cut in that area. Furthermore, the respondents are willing to pay around 1.6 SEK to cut $1 \%$ of the remaining parts.

\subsection{Cost-Benefit analysis}

There are some available estimates of the cost of cutting the yellow floating heart, although not in required detail. However, to provide the authorities with some initial guidance, we use the currently available estimates for a cost-benefit test of a weed management program in Lake Väringen. The general assessment made in this paper can then be extended into greater detail when cost estimates are available in required detail.

The average cost to cut, collect and transport the weed from the site is estimated to around 28,000 SEK per hectare (ha). ${ }^{9}$ For successful control of the weed, it is recommended that the procedure is repeated twice a year. The annual cost is then 56,000 SEK per hectare. The cost estimates were assessed at a time when the water weed covered an area of 50 ha of Lake Väringen (Södergren, 1981). The current area is believed to have increased to 100 ha in the northern parts of Lake Väringen. We further assume that the housing area, the bathing place, the canoe track and the boat places correspond to a surface area of 50 ha covered with

\footnotetext{
${ }^{9}$ The average 1980 cost adjusted for inflation to 2005 was used. A proper cost-benefit analysis of course requires the marginal cost of cutting, but this is not available.
} 
weed, while the other 50 ha are spread over the remaining areas. This means that the cost of cutting the weed in the specific areas would be around 1,400,000 SEK per occasion, and the cost of cutting all the remaining areas would also be around 1,400,000 SEK per occasion. There are around 10,000 households in the municipality of Lindesberg. Consequently, each household would have to pay around 280 SEK per year for controlling and cutting the water weed at the specific areas, assuming that the procedure is repeated twice a year. Moreover, the cost per household to cut $1 \%$ of the remaining part would be around 2.8 SEK per year. We can now calculate the net benefits as follows:

$$
E[N B]=P[\text { Demander }]^{*}(E[\text { WTP } \mid \text { Demander }]-\text { Cost })+P[\text { Non-demander }]^{*}(E[\text { WTP } \mid \text { Non-demander }]-\text { Cost })
$$

Since the non-demanders get disutility by paying for a weed management alternative per se, we single out the demanders as winners if the public good is provided, whereas the nondemanders are the losers since they still have to pay for the management program. However, since we implicitly have assumed that income enters the utility function in a linear fashion we can simply subtract the cost from the expected WTP to obtain the net benefits. The total disutility for non-demanders is thus the cost of the weed management program.

Using equation 8 , the net benefit of cutting the weed in the specific areas is estimated to 367 SEK, whereas the net benefit of cutting $1 \%$ of the remaining areas is estimated to -1.04 SEK. This means that a weed management program to cut the weed in the specific areas passes the simple cost-benefit test, while cutting the remaining parts does not. One crucial aspect of our calculations is of course the costs. If it is only necessary to cut the weed once a year, it would be socially beneficial to also cut the weed in the remaining areas.

As we have discussed, if the program is realized the non-demanders will not benefit; on the contrary, they could be seen as losers since they nevertheless have to pay for the program. There is also a possibility that there are among the demanders, those with a WTP that is less than the cost; remember that we can predict individual WTP from the estimated model. However, if we predict the WTP for cutting at all the specified areas for each demander we find that the lowest net benefit is around 90 SEK. ${ }^{10}$ Consequently, in this particular case all demanders have a positive net benefit.

Finally, we have a very high share of non-respondents. An interesting question is if cutting the weed would have passed the test had we assumed that all non-respondents have a

\footnotetext{
${ }^{10}$ Detailed results are available upon request.
} 
zero WTP. The unconditional WTP for cutting the weed at all the specified places would then have been around 190 SEK, which would not pass a simple cost-benefit test, although it is not very far from the cost of 280 SEK per year.

\section{Discussion and concluding remarks}

The common approach in choice experiment surveys is to include an opt-out alternative in each choice set. However, this approach doesn't make any distinction between demanders and non-demanders. In this paper we suggest an alternative approach where we identify nondemanders before the actual choice experiment and where only those who demand a policy are asked to do the choice experiment. Hence, non-demanders will not be asked to evaluate the various scenarios in the choice experiment. The advantage of our suggested approach is that we can more clearly distinguish between conditional and unconditional WTP. Furthermore, the estimates of the conditional WTP are not affected by the behavior of respondents with zero WTP. In theory, an alternative would be to include an opt-out alternative in each choice set with the assumption that non-demanders would choose the optout alternative in every choice situation. However, it would be more difficult to distinguish between the conditional and unconditional WTP. Conditional WTP provides the policy-maker with additional information about how important the public good is to the welfare of the demanders.

As expected, our findings suggest that respondents who live close to the lake are more likely to have a positive demand for the lake. The most attractive attribute of weed management is to cut the weed at the bathing place, where the mean WTP is around 200 SEK. Then come the boat place and the housing area attribute, each with a mean WTP of around 100 SEK. Finally, the least important attribute seems to be to the canoe track. As a concluding remark, removing the weed in the specific areas of Lake Väringen passed the cost-benefit test, whereas doing it in the remaining areas did not. 


\section{References}

Alpizar, F., F. Carlsson and P. Martinsson (2003) Using choice experiments for non-market valuation, Economic Issues 8, 83-110

Bennett, J. and R. Blamey (2001) The Choice Modelling Approach to Environmental Valuation, Cheltenham: Edward Elgar.

Carlsson, F., P. Frykblom and C.J. Lagerkvist (2005) Using cheap-talk as a test of validity in choice experiments, Economics Letters 89, 147-152.

Carlsson, F., P. Frykblom and C. Liljenstolpe (2003) Valuing wetland attributes: an application of choice experiments, Ecological Economics 47, 95-103.

Cummings, R.G. and Taylor, L.O. (1999). Unbiased Value Estimates for Environmental Goods: A Cheap Talk Design for the Contingent Valuation Method. American Economic Review 89, 649-65.

Clinch, J. and P. Murphy (2001) Modelling winners and losers in contingent valuation of public goods: Appropriate welfare measures and econometric analysis, Economic Journal $111,420-443$.

Eriksson, M. (2005) Sjögull (Nymphoides peltata) i Galten - en möjlig invasionsart. Examensarbete, Institutionen för Miljöanalys, SLU (In Swedish).

Greene, W. (2000) Econometric Analysis, New Jersey: Prentice-Hall

Haab, T. (1999) Nonparticipation or misspecification? The impacts of nonparticipation on dichotomous choice contingent valuation, Environmental and Resource Economics 14, 443-461.

Hensher, D. and W. Greene (2003). The mixed logit model: The state of practice. Transportation 30, 133-176.

Hanemann, M. (1984) Welfare evaluations in contingent valuation experiments with discrete response, American Journal of Agricultural Economics 66, 332-341.

Josefsson and Andersson (2001) The Environmental Consequences of Alien Species in the Swedish Lakes Mälaren, Hjälmaren, Vänern and Vättern, Ambio 8, 514-521

Kuhfeld, W. (2001) Multinomial logit, discrete choice modeling. An introduction to designing choice experiment and collecting, processing and analyzing choice data with SAS, SAS Institute TS-643.

Kriström, B. (1997) Spike models in contingent valuation, American Journal of Agricultural Economics 79, 1013-1023.

Layton, D. and G. Brown (2000) Heterogeneous preferences regarding global climate change, Review of Economics and Statistics 82, 616-624. 
Larson D and Willén E (2006) Non-indigenous and invasive water plants in Sweden (in Swedish with English abstract). Svensk Botanisk Tidskrift 100: 5-15

List, J. and P. Sinha (2004) Using choice experiments to value non-market goods and services. Working paper. University of Maryland and NBER.

Louviere, J.J. (1988) Analyzing Decision Making: Metric Conjoint Analysis. Newbury Park: Sage.

Louviere, J., D. Henser and J. Swait (2000) Stated Choice Methods. Cambridge: Cambridge University Press.

Nunes, P. and J. van den Bergh (2004) Can people value protection against invasive marine species? Evidence from a joint TC-CV survey in the Netherlands, Environmental and Resource Economics 28, 517-532.

Södergren, S. (1981) Försöksbekämpning av sjögull i sjön Väringen. Länsstyrelsen i Örebro län, Naturvårdsenheten (in Swedish).

Wynand, P and B. van Praag (1981) The demand for deductibles in private health insurance: A probit model with sample selection, Journal of Econometrics 17, 229-252. 


\section{Appendix A}

Figure 1. Example of choice set used in the questionnaire

\begin{tabular}{|l|c|c|}
\hline & Alternative 1 & Alternative 2 \\
\hline $\begin{array}{l}\text { Mechanical control of } \\
\text { the water weed at the } \\
\text { following chosen sites }\end{array}$ & 3. At the Canoe track & $\begin{array}{c}\text { 1. At Frövi } \\
\text { 4. At the boat place }\end{array}$ \\
\hline $\begin{array}{l}\text { Mechanical control of } \\
\text { the water weed at } \\
\text { remaining sites }\end{array}$ & $40 \%$ & $40 \%$ \\
\hline $\begin{array}{l}\text { Annual additional } \\
\text { cost for the household }\end{array}$ & 150 kronor & 500 kronor \\
\hline $\begin{array}{l}\text { Your Choice } \\
\text { (mark one alternative) }\end{array}$ & & \\
\hline
\end{tabular}

Figure 2. Map of North Väringen

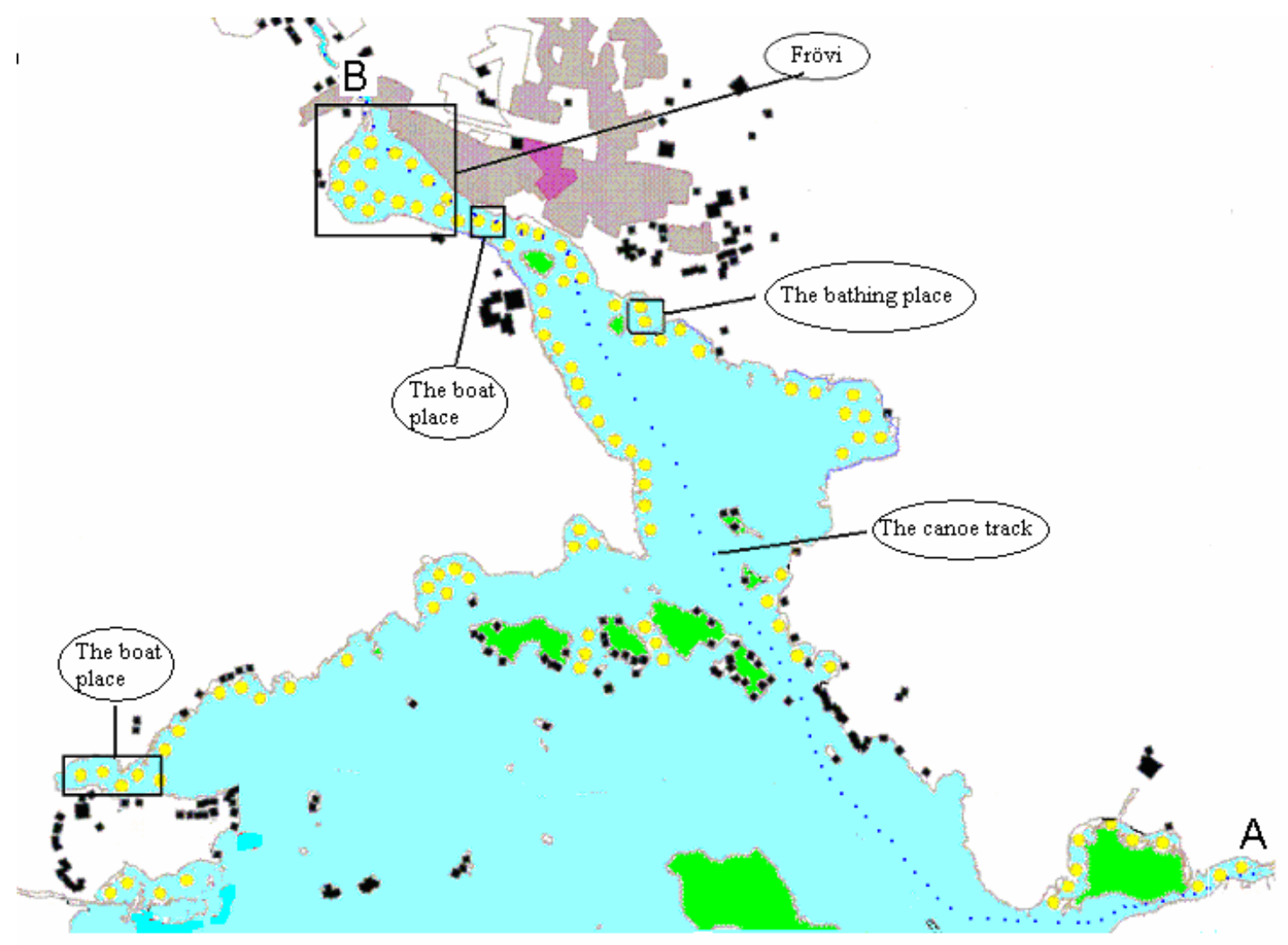

